\title{
PENGARUH BRAND IMAGE, SERVICE QUALITY, DAN CUSTOMER RELATIONSHIP MANAGEMENT TERHADAP CUSTOMER LOYALTY
}

\author{
Samuel Hendy \\ Program Studi Magister Manajemen Universitas Tarumanagara \\ samuelhendyy@gmail.com \\ Keni \\ Program Studi Magister Manajemen Universitas Tarumanagara
}

\begin{abstract}
This research is being shown in order to learn how brand image, service quality and customer relationship management can affect customer loyalty one of these coffee shops in Jakarta. This research can be classified as quantitative and descriptive research which consist of primary data that being gather by online questionnaire, in other word survey. These coffee shops customer that located in Jakarta are the sample in this research. The data that has been gathered are being collected from 150 customers. As the result, this research shown from these coffee shops customer in Jakarta are 1) Brand image affect the customer loyalty in positive way. 2) Service quality give positive impact toward customer loyalty. 3) There are positive clout that customer relationship management give toward customer loyalty
\end{abstract}

\begin{abstract}
Abstrak : Penelitian ini ditunjukkan untuk mengetahui pengaruh dari brand image, service quality, dan customer relationship management terhadap customer loyalty salah satu kedai kopi di Jakarta, penelitian ini merupakan penelitian kuantitatif dan penelitian deskriptif dengan data primer yang didapat dari distribusi kuisioner online. Pelanggan kedai kopi yang berlokasi di Jakarta adalah sampel dari penelitian ini dan sampel diambil sebanyak 150 pelanggan. Singkatnya, kesimpulan penelitian dari pelanggan salah satu kedai kopi di Jakarta adalah 1) Brand image berpengaruh secara positif terhadap customer loyalty, 2) Service quality berpengaruh secara positif terhadap customer loyalty, 3) Customer Relationship Management berpengaruh secara positif terhadap customer loyalty.
\end{abstract}

Keywords : Brand Image, Service Quality, Customer Relationship Management, Customer Loyalty

\section{PENDAHULUAN}

Dewasa ini mal atau pusat perbelanjaan bukan lagi menjadi satu-satunya tempat tujuan untuk menghabiskan waktu di akhir pekan, kecuali yang memang mempunyai tujuan untuk berbelanja. Tempat yang digemari sekarang ini adalah coffee shop atau kedai kopi, baik dari kalangan remaja sampai dengan dewasa, pasti pernah mengunjungi kedai kopi. Para pengunjung rela menghabiskan waktu berjam-jam hanya dengan menikmati secangkir kopi dan beberapa makanan ringan saja. Selain menjadi tempat untuk menikmati kopi, berbincang bersama teman, kedai kopi sering digunakan menjadi tempat meeting atau pertemuan kerja lainnya. Kedai kopi ini banyak dijumpai di supermarket karena mereka memilih pasar kelas menengah ke atas.

Menurut data survey dari Top Brand Award, kedai kopi ini menduduki peringkat kedua setelah kompetitornya dengan perbedaan yang signifikan yaitu sekitar 34,5\%. Keberhasilan kompetitor menjadi urutan pertama karena memiliki banyak keunggulan sehingga bisa mendapatkan loyalitas dari para pelanggan. Loyalitas pelanggan perlu diperoleh karena pelanggan yang setia akan aktif berpromosi, memberikan rekomendasi kepada keluarga dan sahabatnya, menjadikan produk sebagai pilihan utama, dan tidak mudah pindah (Mardalis, 2005). Menurut Kotler dan Armstrong (2018), loyalitas dari konsumen berasal dari pemenuhan 
harapan pelanggan, sedangkan harapan tersebut berasal dari pengalaman pembelian sebelumnya, opini teman atau relatif atau informasi dari para tim pemasaran atau kompetitor.

Timbulnya rasa loyal dari pelanggan dipengaruhi oleh banyak faktor, menurut penelitian Kristian (2014), total quality service, customer relationship management, dan customer satisfaction secara positif dan signifikan mempengaruhi loyalitas pelanggan. Menurut penelitian Ogba dan Tan (2009), brand image dan komitmen merupakan faktor positif yang mempengaruhi loyalitas pelanggan. Brand image adalah suatu gambaran atau pandangan dari pelanggan terhadap suatu brand/produk dan merupakan salah satu faktor positif yang mempengaruhi loyalitas pelanggan. Menurut penelitian Saleem dan Raja (2014), menemukan brand image yang kuat akan langsung berhubungan dengan customer loyalty yang kuat juga

Selain brand image, ada faktor lain yang mempengaruhi adalah customer relationship management. Menurut penelitian Kristian (2014), customer relationship management memiliki efek positif pada loyalitas pelanggan, karena dengan melalui customer relationship management, perusahaan berusaha untuk menarik perhatian pelanggan, karena pada akhirnya loyalitas pelanggan akan berakibat pada performa perusahaan. Service quality juga merupakan hal yang mempengaruhi customer loyalty, penelitian Zeithaml, Berry, dan Parasuraman (1996) menyatakan bahwa pelanggan yang tidak mengalami masalah dalam pelayanan mempunyai nilai loyalitas yang tinggi.

\section{TELAAH KEPUSTAKAAN Brand Image}

Keller (1993: 3) mengungkapkan bahwa "Brand image is defined here as perceptions about a brand as a reflected by the brand associations held in consumer memory." Dapat disimpulkan bahwa brand image merupakan suatu hal yang melekat di pikiran pelanggan tentang bagaimana persepsi pelanggan terhadap suatu brand jika brand tersebut ada di hadapan pelanggan.

\section{Service Quality}

"Service quality would include not only quality final service but also production and delivery process of services. Thus the importance of employee involvement in process redesign and commitment to the improvement of the final tourism product or service comes into picture.”, (Kumra, 2008: 424), Dapat disimpulkan bahwa service quality merupakan suatu aktivitas yang dilakukan oleh perusahaan untuk memenuhi harapan pelanggan dalam pemenuhan kebutuhan dan keinginan. Aktivitas yang dimaksudkan adalah melalui pelayanan atau jasa yang diberikan oleh perusahaan agar pelanggan merasa puas.

\section{Customer Relationship Management}

Menurut Gordon (2002: 1), “Customer relationship Management is a series of strategies and processes that create new and mutual value for individual customers, builds preference for their organizations and improves business results over a lifetime of association with their customer." Dapat disimpulkan bahwa customer relationship management merupakan suatu strategi yang harus dilakukan oleh perusahaan untuk menjaga hubungan baik dengan pelanggan dalam level organisasional untuk mencapai profitabilitas yang lebih.

\section{Customer Loyalty}

Menurut Kottler dan Keller (2016: 153) loyalty dapat didefinisikan sebagai "a deeply held commitment to rebuy or repatronize a preferred product or service in the future despite situational influences and marketing efforts having the potential to cause switching behavior." Dapat disimpulkan customer loyalty adalah suatu sikap positif terhadap suatu produk atau jasa sehingga pelanggan akan terus melakukan pembelian secara berulang meskipun ada pengaruh dari pihak lain. 


\section{Kaitan antar Variabel}

- Kaitan antara Brand Image dan Customer Loyalty

Dalam penelitian yang dilakukan oleh Ogba dan Tan (2009), dijelaskan bahwa brand image yang kuat pastinya akan memberikan dampak positif pada customer loyalty sehingga pelanggan akan loyal kepada perusahaan. Hal serupa juga diungkapkan oleh Saleem dan Raja (2014) mengungkapkan bahwa adanya hubungan positif langsung yang kuat antara brand image dengan customer loyalty, artinya semakin kuat citra merek perusahaan maka tingkat kesetiaan pelanggan akan semakin meningkat terhadap perusahaan tersebut. Berdasarkan uraian tersebut, hipotesis penelitian $(\mathrm{H1})$ adalah:

H1 : Terdapat pengaruh positif pada Brand Image terhadap Customer Loyalty

- Kaitan antara Service Quality dan Customer Loyalty

Dalam penelitian Kheng, et al. (2010), menunjukkan bahwa peningkatan service quality dapat meningkatkan loyalitas pelanggan. Dalam penelitian Ghane, et al. (2011), menunjukkan bahwa service quality mempunyai hubungan langsung yang kuat terhadap customer loyalty. Artinya, jika service quality ditingkatkan performanya maka tingkat customer loyalty juga akan meningkat. Berdasarkan uraian tersebut, hipotesis penelitian $\left(\mathrm{H}_{2}\right)$ adalah :

$\mathrm{H}_{2}$ : Terdapat pengaruh positif pada Service Quality terhadap Customer Loyalty

- Kaitan antara Customer Relationship Management dan Customer Loyalty

Dalam penelitian Kristian dan Panjaitan (2014), menjelaskan bahwa customer relationship management memiliki efek yang signifikan terhadap customer loyalty. Artinya jika ingin meningkatkan customer loyalty maka perusahaan pertama-tama harus meningkatkan customer relationship management yang lebih baik. Dalam penelitian Khedkar (2015), mengemukakan bahwa customer relationship management yang efektif dapat meningkatkan customer loyalty. Berdasarkan uraian tersebut, hipotesis penelitian $\left(\mathrm{H}_{3}\right)$ adalah :

$\mathrm{H}_{3}$ : Terdapat pengaruh positif pada Customer Relationship Management dan Customer Loyalty

\section{METODOLOGI PENELITIAN}

Penelitian ini merupakan penelitian deskriptif cross-sectional, yaitu pengumpulan data hanya sekali dan sumber data didapat dari data primer. Metode pengambilan sampel adalah dengan non-probability sampling terhadap 150 pelanggan kedai kopi di Jakarta. Teknik analisis data yang digunakan adalah dengan pengujian asumsi klasik dan dilanjutkan dengan analisis regresi ganda dengan bantuan aplikasi SPSS. Dalam tabel 1 menunjukkan instrumen masingmasing variabel beserta sumbernya.

Tabel 1. Variabel dan Pengukuran

\begin{tabular}{|l|c|c|}
\hline \multicolumn{1}{|c|}{ Variabel } & Item & Sumber \\
\hline Variabel bebas: & & \\
Brand Image & 5 & Andreani, et al. (2014) \\
Service Quality & 17 & $\begin{array}{c}\text { Parasuraman, } \text { et al. (1988) } \\
\text { Customer Relationship Management }\end{array}$ \\
& 10 & Mawarni, et al, (2016) \\
\hline Variabel terikat: & 5 & Lewis \& Soureli (2006) \\
Customer Loyalty & &
\end{tabular}

Penelitian dilakukan dengan distribusi kuisioner online yang kemudian diolah dengan analisis regresi ganda untuk mengetahui pengaruh masing-masing variabel bebas terhadap variabel terikat.

\section{HASIL PENELITIAN DAN PEMBAHASAN}

Pada tabel 2 merupakan hasil analisis data, sehingga diperoleh hasil bahwa masingmasing variabel bebas secara positif mempengaruhi variabel terikat dan menunjukkan bahwa 
semua hipotesis tidak ditolak. Dari tabel juga dapat terlihat variabel service quality memiliki pengaruh terbesar terhadap customer loyalty dibandingkan kedua variabel bebas lainnya.

Tabel 2. Hasil Analisis Regresi

\begin{tabular}{|c|c|c|c|c|}
\hline \multicolumn{2}{|c|}{ Hipotesis } & Koefisien & Sig. & Hasil \\
\hline $\mathrm{H}_{1}$ & Brand image $\rightarrow$ customer loyalty & 0,221 & 0,003 & Tidak ditolak \\
\hline $\mathrm{H}_{2}$ & Service quality $\rightarrow$ customer loyalty & 0,498 & 0,000 & Tidak ditolak \\
\hline $\mathrm{H}_{3}$ & $\begin{array}{c}\text { Customer relationship management } \\
\rightarrow \text { customer loyalty }\end{array}$ & 0,401 & 0,000 & Tidak ditolak \\
\hline
\end{tabular}

Hasil pengujian hipotesis pertama menunjukan bahwa brand image berpengaruh secara positif terhadap customer loyalty. Hal ini menunjukkan bahwa responden kedai kopi sependapat bahwa perusahaan tersebut memiliki nama yang baik dan dikenal oleh banyak kalangan. Hasil penelitian ini sesuai dengan hasil penelitian terdahulu oleh Ogba dan Tan (2009) yang menunjukan bahwa brand image akan secara positif meningkatkan customer loyalty. Dalam penelitian Saleem dan Raja (2014) mengungkapkan bahwa adanya hubungan positif langsung yang kuat antara brand image dengan customer loyalty. Dari hasil penelitian yang didapat, brand image merupakan suatu hal yang melekat di pinggiran pelanggan terhadap suatu merek/brand sebagai contoh jika merek tersebut menyajikan sesuatu dengan baik pastinya konsumen akan mengingat hal tersebut sehingga setiap kali menjadi bahan pembicaraan pastilah hal positif yang akan dibicarakan mengenai merek tersebut.

Hasil pengujian hipotesis kedua menunjukan bahwa service quality berpengaruh secara positif terhadap Customer Loyalty. Hasil penelitian ini sesuai dengan hasil penelitian terdahulu oleh Kheng, et al. (2010), yang menunjukkan bahwa peningkatan service quality dapat meningkatkan loyalitas pelanggan. Dalam penelitian Ghane, et al. (2011), menunjukkan bahwa service quality mempunyai hubungan langsung yang kuat terhadap customer loyalty. Dari hasil penelitian yang didapat, pegawai kedai kopi telah memberikan dampak positif, berupa pelayanan yang baik, ramah, dan cepat tanggap sehingga pelanggan merasa nyaman ketika mengunjungi kedai kopi. Pelayanan yang nyaman membuat pelanggan kembali berkunjung. Jadi jika kedai kopi meningkatkan lagi service quality perusahaannya maka hal tersebut akan memberikan dampak positif terhadap tingkat kesetiaan dari pelanggan-pelanggannya.

Hasil pengujian hipotesis ketiga menunjukkan bahwa Customer relationship management berpengaruh secara positif terhadap customer loyalty. Hasil penelitian ini sesuai dengan hasil penelitian terdahulu oleh Kristian dan Panjaitan (2014), yang menjelaskan bahwa customer relationship management memiliki efek yang signifikan terhadap customer loyalty. Dalam penelitian Khedkar (2015), mengemukakan bahwa customer relationship management yang efektif dapat meningkatkan customer loyalty. Dari hasil penelitian yang didapat, kedai kopi sangat menjaga hubungan baik dengan pelanggan sehingga membuat pelanggan merasa nyaman. Keluhan, kritik dan saran dapat diterima dengan baik oleh pegawai, dan dilanjutkan kepada pusat untuk dilakukan peningkatan pada layanan ataupun produk yang dijual sehingga membuat pengunjungnya semakin nyaman. Selain itu kedai kopi juga terus melakukan update mengenai informasi atau promo terbaru seperti lewat email, media social dan lewat iklan-iklan.

\section{KESIMPULAN DAN SARAN}

Hasil penelitian menunjukkan bahwa variabel brand image, service quality, dan customer relationship management berpengaruh secara positif terhadap customer loyalty. Dari hasil tersebut peneliti memberikan saran agar perusahaan dapat lebih memperhatikan faktor brand image, service quality, dan customer relationship management dalam melakukan pemasaran karena dapat meningkatkan loyalitas pelanggan secara langsung. Bagi penelitian selanjutnya, disarankan untuk memperluas jangkauan pengambilan sampel dan wilayah penelitian serta menambah variabel lainnya yang berpengaruh terhadap customer loyalty. 


\section{IMPLIKASI MANAJERIAL}

Berdasarkan hasil penelitian, maka dapat disampaikan beberapa implikasi manajerial yang bisa diterapkan oleh perusahaan. Melihat dari hasil pengaruh positif oleh brand image, service quality, dan customer relationship management terhadap customer loyalty, maka dihimbau agar perusahaan lebih menjaga reputasi yang baik di mata pelanggan sehingga nama baik brand perusahaan tetap terjaga. Untuk variabel service quality, perusahaan dihimbau untuk melakukan pengecekan ulang apakah perlengkapan di kafe sudah cukup memadai atau belum, meningkatkan mutu pelayanan dari para karyawan seperti inisiatif membantu dari para karyawan, dan karyawan yang mau menanggapi keluhan pelanggan dengan baik. Perusahaan juga dianjurkan untuk terus menerus meningkatkan customer relationship management, hal ini dapat dilakukan dengan cara meningkatkan profesionalisme karyawan dalam menangani pelanggan, meningkatkan kemudahan dalam melakukan transaksi atau pembayaran, dan penggunaan media social untuk mendapatkan informasi terbaru mengenai perusahaan.

\section{DAFTAR PUSTAKA}

Andreani, et al, (2012), "The Impact of Brand Image, Customer Loyalty with Customer Satisfaction as mediator in Mcdonald's", Jurnal Manajemen dan Kewirausahaan, 14(1), 63-70.

Bowen, Shiang-Lih Chen, (2001), The relationship between customer loyalty and customer satisfaction, International Journal of Contemporary Hospitality Management, Vol. 13 Iss: 5 , pp. $213-217$.

Cassia, et al, (2017), "The effects of goods-related and service-related B2B brand images on customer loyalty", Journal of business \& industrial marketing, 32(5).

Fianto, et al, (2014), "The Influence of Brand Image on Purchase Behaviour Through Brand Trust", Business Management and Strategy, 5(2).

Flint, et al, (2010), "Customer Value Anticipation, Customer Satisfaction and Loyalty: An Empirical Examination", Industrial Marketing Management, 12

Ghane, et al, (2011), "Full Relationship Among E-Satisfaction, E-Trust, E-Service Quality and E-Loyalty: The Case of Iran E-Banking”, Journal of Theoritical and Applied Information Technology, 33(1).

Ghozali, Imam, (2018), “Aplikasi Analisis Multivatiate dengan program IBM SPSS 25 edisi 9", Badan Penerbit Universitas Diponegoro: Semarang.

Gordon, Ian, (2002) "Best Practices: Customer Relationship Management", Ivey Business Journal.

Hair, et al, (2010), "Multivariate Data Analysis, 7/e", Pearson: Prentice Hall.

Hassan, et al, (2013), "Measuring Customer Satisfaction and Loyalty Through Service Fairness, Service Quality and Price Fairness Perception: An Empirical Study of Pakistan Mobile Telecommunication Sector", Science International, 25(4), 971-980.

Hsieh, Ming-Huei \& Lindridge, Andrew, (2005), "Universal appeals with local specifications", Journal of Product \& Brand Management, 14(1), pp. 14-28.

Keller, Kotler (2016) 'Marketing Management', edisi 15, Global Edition, USA: Pearson.

Keller, Kevin Lane, (1993), "Conceptualizing, Measuring, and Managing Customer-Based Brand Equity", Journal of Marketing, 57(1), pp.1-22.

Khedkar, E.B., (2015) "effect of customer relationship management on customer satisfaction and loyalty", International Journal of management, 6(5), pp. 1-7.

Kheng, Lo Liang, et al. (2010) "The impact of service quality on customer loyalty: A study of banks in penang, Malaysia”, International journal of marketing studies, 2(2).

Kotler, P., \& Amstrong, G. (2018). Principles of marketing. New Jersey: Pearson Prentice Hall

Kristian, Feliks A.B., \& Panjaitan, Hotman, (2014), "Analysis of customer loyalty through total quality service, customer relationship management and customer satisfaction", International journal of evaluation and research in education, 3(3), pp. 142-151. 
Kulpa, Jason (2017), “Why Is Customer Relationship Management So Important?”, available at https://www.forbes.com/sites/forbesagencycouncil/2017/10/24/why-is-customerrelationship-management-so-important/\#37c879097dac (accessed on March $25^{\text {th }} 2018$ )

Kumra, Rajeev, (2008) "Service Quality in Rural Tourism: A Perspective Approach", Conference on Tourism in India-Challenges Ahead, India.

Lahap, et al, (2015), "A Study of Brand Image towards Customer's Satisfaction in the Malaysian Hotel Industry", 6th International Research Symposium in Service Management, 6, 11-15.

Mardalis, Ahmad (2005) "Meraih Loyalitas Pelanggan”, Benefit, 9(2), 111-119

Lewis, Barbara R \& Soureli, Magdalini, (2006) "The Antecedents of Consumer Loyalty in Retail Banking", Journal of Consumer Behaviour, 5:15-31.

Martinez, Eva \& Pina, Jose M., (2003) "The negative impact of brand extensions on parent brand image", Journal of Product \& Brand Management, 12(7), pp. 432-448.

Mawarni, et al, (2016), "Pengaruh Customer Relationship Management terhadap Loyalitas Pelanggan PT Kereta Api Indonesia”, SEGMEN: Jurnal Manajemen dan Bisnis, 12(1C)

Nyadzayo, Munyaradzi W \& Khajehzadeh, Saman (2016), "The Antecedents of customer loyalty: A moderated mediation model of customer relationship management quality and brand image", Journal of Retailing and Consumer Services, 30, pp. 262

Ogba, Ike-Elechi, \& Tan, Zhenzhen, (2009), "Exploring the impact of brand image on customer loyalty and commitment in China", Journal of Technology Management, 4(2), pp. 132144.

Parasuraman, et al, (1985), "A Conceptual Model of Service Quality and Its Implications for Future Research", The Journal of Marketing, 49(4), pp 41-50.

Parasuraman, et al, (1988) "SERVQUAL: A Multiple-Item Scale for Measuring Consumer Perceptions of Service Quality", Journal of Retailing, 64(1).

Plessis, M. Du, Boon, J.A., (2004) "Knowledge management in eBusiness and Customer Relationship Management: South African Case Study Findings", International Journal of Information Management, 24 pp. 73-86.

Pratminingsih, et al, (2013), "Factors Influencing Customer Loyalty Toward Online Shopping”, International Journal of Trade, Economics and Finance, 4(3).

Saleem, Hamad \& Raja, Sarfraz, (2014), "The Impact of Service Quality on Customer Satisfaction, Customer Loyalty and Brand Image: Evidence from Hotel Industry of Pakistan", Middle-East Journal of Scientific Research, 19(5), pp. 706-711.

Sekaran, Uma \& Bougie, Roger, (2016), "Research Methods for Business", United Kingdom: John Wiley \& Sons

Sugianto, jimmy \& Sugiharto, Sugiono, (2013), “Analisa Pengaruh Service Quality, Food Quality, dan Price terhadap Kepuasan Pelanggan Restoran Yung Ho Surabaya”, Jurnal Manajemen Pemasaran Petra, 1(2), 1-10.

Sugiyono, (2016), “Metode Penelitian Kuantitatif, Kualitatif, dan R\&D”, Penerbit Alfabeta: Bandung.

Tjiptono, Fandy (2014) "Pemasaran Jasa", Yogyakarta: Penerbit Andi Offset.

Topbrand (2017), "top brand index 2017 fase 2, available at http://www.topbrandaward.com/top-brand-survey/survey-result/top_brand_index_2017_fase_2 (accessed on February, 20 2017 )

Zeithaml, Valarie A., Berry, Leonard L., \& Parasuraman, A., (1996) "The behavioral consequences of service quality", Journal of marketing. 